\title{
Network design and operational modelling for construction green supply chain management
}

\author{
Pengfei Zhou*, Dong Chen and Qiuliang Wang
}

Faculty of Infrastructure Engineering, Dalian University of Technology, Dalian, China

CHRONICLE ABSTRACT

\begin{tabular}{l} 
Article history: \\
Received September 252012 \\
Received in revised format \\
November 162012 \\
Accepted November 162012 \\
Available online \\
16 November 2012 \\
\hline Keywords: \\
Green Supply Chain Management \\
Mathematical Programming \\
Reverse Logistics \\
Environmental Performance
\end{tabular}

Article history:

2012

Available online

Keywords:

Green Supply Chain Management

Reverse Logistics

\begin{abstract}
Based on studying organizational structure of Construction Green Supply Chain Management (CGSCM), a mathematical programming model of CGSCM was proposed. The model aimed to maximize the aggregate profits of normalized construction logistics, the reverse logistics and the environmental performance. Numerical experiments show that the proposed approach can improve the aggregate profit effectively. In addition, return ratio, subsidies from governmental organizations, and environmental performance were analyzed for CGSCM performance. Herein, the proper return, subsidy and control strategy could optimize construction green supply chain.
\end{abstract}

\section{Introduction}

The construction industry consumes large amounts of resources and energy. The implementation of traditional construction industry supply chain mainly aims on maximizing separate profits of the supply chain enterprises, where their own cost are taken into account while the induced environmental performance, the impact of upstream and downstream enterprises and how to deal with waste and recycling are not considered adequately. From the perspective of the sustainable development of society and enterprises, Green Supply Chain Management (GSCM) introduces the novel design idea, which involves green purchase, green production, green consumption and green recycling in the integrated supply chain, to optimize the integrated supply chain in environment management. GSCM is an effective way to save energy and reduce pollution, which could improve the competitiveness of construction industry, environmental protection and is of great significance for sustainable development strategy.

According to a database of over 4000 manufacturing facilities from 7 different countries, the determinants, motivations and effects for the implementation of GSCM were analyzed and showed that GSCM could effectively improve environmental indices (Francesco \& Fabio, 2010). An assessment framework about green construction industry was developed, which consisted of assessment criteria,

* Corresponding author. Tel.: +86-411-84708522; Fax: +86-411-84674141

E-mail: pfzhou@yeah.net (P. Zhou)

(c) 2013 Growing Science Ltd. All rights reserved.

doi: 10.5267/j.ijiec.2012.011.001 
relationship levels, detailed descriptions, assessment classes and assessment procedures and provided a roadmap for the improvement of supply chain relationships (Xian Hai, 2010). According to the conceptual framework of GSCM, integrated logistics operational problems of GSCM were discussed, and the multi-objective linear programming models were formulated respectively to systematically optimize manufacturing supply chain (Jiuh-Biing, 2008) and nuclear power generation progress (JiuhBiing et al., 2005).

A proper design of environmental regulation pricing strategy was demonstrated and found that the government should opt to gradually raise regulation standards so that rational manufacturers would gradually improve their product recyclability, which was able to promote Extended Product Responsibility (Yenming \& Jiuh-Biing, 2009). Due to construction peculiarities, four specific roles in construction supply chain management were studied, practical initiatives in each role to advance the construction supply chain were analyzed and three main conclusions contained the construction supply chain had a large quantity of waste, and problems were largely caused by obsolete, myopic control of the construction supply chain (Ruben \& Lauri, 2000). Based on a synergistic integration of relevant resulted from a series of related research studies, a relationally reinforced supply chain integration model was developed to supply the basic transactional contractual links and to release the latent energies needed to elevate construction industries in many countries (Ekambaram et al., 2003).

A systematic approach for dealing with potential adverse environmental impacts at the pre-construction stage was introduced and a consistent basis of comparisons for future eco-labelling and environmental benchmarking among construction companies and construction sites was provided (Marta et al., 2009). How organizations balance short-term profitability and long-term environmental sustainability were studied when making supply chain decisions under uncertainty to help explain the decisions organizations make when dealing with strategic trade-offs among the economic, environmental and social elements of the triple-bottom-line (Zhao Hui \& Mark, 2011). A number of operational and environmental performance measures within a closed-loop supply chain were investigated, using a mathematical model in the form of a linear programming formulation and results were presented for a number of scenarios through a realistic network instance (Turan et al., 2011).

From the perspective of relationship management, a framework for integrated construction supply chain management was developed to guide the effective implement of supply chain management in construction industry, which includes contractor (supplier) selection, conflict management, risk management, innovation management, performance management and information supporting system (Yao Wu \& Xiao Long, 2004). The studies showed that integrated construction supply chain management was more applicable and effective than the traditional construction management.

A construction supply chain network model was used to analyze the complexity, support reconfiguration, identify the bottlenecks, and prioritize company's resources (Jack et al., 2010). The implementation of the partnership development process was explored, and the utility of a methodology that can be used by practitioners in the construction industry to facilitate the development of effective partnerships was proposed to improve the partnership development process and thence to gain competitiveness (Ander et al., 2007).

The integration of forward and reverse logistics was investigated and a generalized closed-loop model for the logistics planning by formulating a cyclic logistics network problem into an integer linear programming model was proposed, which was able to support the logistic decisions in a closed-loop supply chain efficiently and accurately (Hsiao-Fan \& Hsin-Wei, 2010). An integrated life cycle environmental impact assessment model which was applicable for construction phase was presented, and the results indicate that the proposed model could effectively quantify the environmental impacts of construction processes, and could be potentially used as a tool for contractors to select environmentally friendly construction plans (Xiao Dong et al., 2010). 
The above analysis shows that GSCM is the important part of green construction industry, which has caused the general concern by researchers, but the related studies for the integrated operation optimal model of CGSCM is inefficient. Firstly, the coordination complex, large-scale and long period of the CGSCM and the variable condition of the inbound logistics (steels, cement, sand, bricks, machineries and equipments) and the outbound logistics (reuse materials) make CSCM more difficult. Secondly, the researches on the CSCM are mainly from the perspective of supply chain optimization and that lack of the concepts of green management such as reverse logistics, regulations and behaviour from government. The implementation of CGSCM is to optimize the integrated process including design, procurement, transportation, construction and recycling. Based on analyzing CGSCM, the operation optimal model of CGSCM is proposed and the influence rules of the key parameters for the performance of the supply management are discussed.

\section{Network Design of construction green supply chain}

\subsection{Network Nodes Analysis}

The organizational structure of CGSCM is illustrated in Fig. 1 and 2, which is composed of: (1) construction supply chain (cc for short) members, including supplier of construction raw-materials, supplier of construction materials, construction enterprise, supplier of decorative raw-materials, supplier of decorative materials, supplier of equipment leasing, project owners, construction supervising units, designing institute, end-customers. (2) Reverse logistics chain (rc for short) members, including reprocessed center of decorative materials, reprocessed center of construction materials, final disposal location. (3) The interior of construction enterprises, including overall contractor, subcontractor, project of the department overall contractor, project department of the subcontractor, recycling center. (4) The environmental protection administration (EPA) of the government, considering the potential effects oriented from corresponding governmental regulations. Accordingly, the organizational members are linked with different lines of physical flow, reverse flow, information flow and cash flow respectively.

\subsection{Network Nodes}

The primary nodes in the organizational structure of CGSCM are as follows.

(1) Supplier of construction raw-materials and supplier of construction materials, which are the logistics starting point of the entire Construction Green Supply Chain.

(2) Construction enterprise. The interior logistics of construction enterprise is divided into forward logistics and reverse logistics. Reverse logistics is subdivided into three classes: primary, second and third recovery. In the primary recovery, the surplus materials return to construction process timely, which is complete in the interior of project department of the subcontractor. In second recovery, unnecessary construction materials and idle equipments in one project department, such as leasing equipment, materials and recycle package, which might be used in another project department, are sent to recycling center and used in rest project departments after coordinating or returned to supplier when project is completed and materials and equipments are not required. In third recovery, the waste construction materials generated in the construction process, such as waste and disposable package, are transported to reprocessed center of construction materials for more specialized treatment.

(3) Project owner. Project owners propose detailed green performance requirements to guide, supervise and evaluate behaviours of contractors. Thereby, it can promote the enthusiasm of green construction of contractors.

(4) Construction supervising units. The green supervision awareness of the construction supervising units plays an important role in the green control of project construction and the entire supply chain. 
(5) Designing institute. As a relatively independent node, designing institute consider green factors in the planning and design stage, such as the pre-control of the construction materials selection.

(6) Environmental protection agency of the government. On the one hand, environmental protection agency of the government can supervise and charge recycling fee from construction enterprise according to the quantity of the construction materials, which can promote the construction enterprise consider green factors in suppliers selection and construction process. On the other hand, it provides corresponding subsidies to reprocessed center of construction materials according to the different waste materials so that the reverse logistics supply chain runs smoothly.

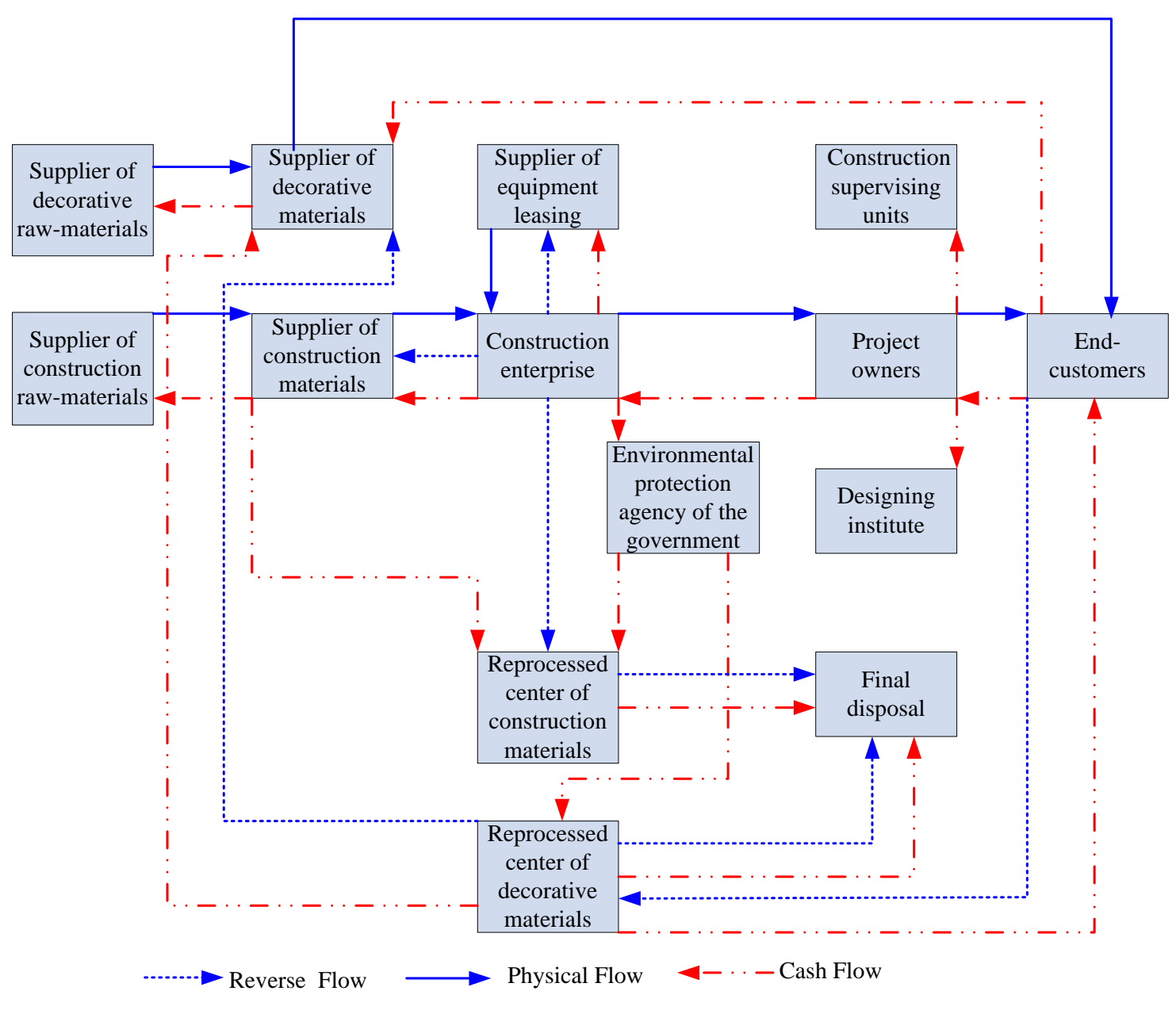

Fig. 1. Organizational structure of CGSCM

(7) End-customers. Make the option of consumption green and the requirements of the end-customers should be valued. At the same time, end-customers should have the awareness of the green consumption.

(8) Reprocessed center of construction materials. As a key node in the reverse logistics, it receives the waste materials from project department of construction enterprise. After reprocessed procedure, some waste materials can re-enter the supply chain through the construction materials suppliers. The final wastes are transported to proper locations for final treatment. And the impact on the environment can be minimized in the entire process. 


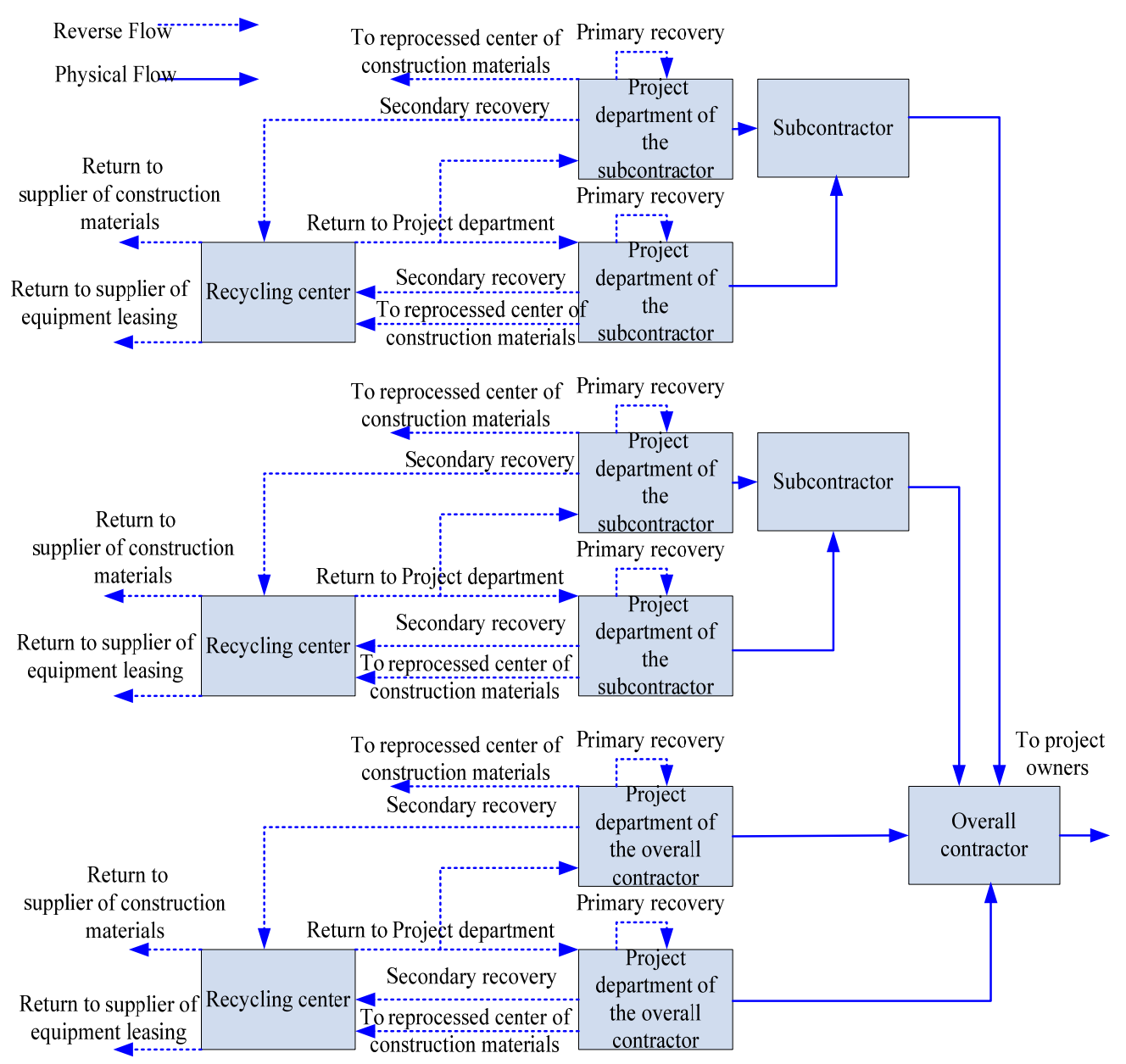

Fig. 2. Organizational structure of Internal of construction enterprises of CGSCM

\section{Operational model of CGSCM}

\subsection{Problem Statement}

According to the organizational structure model of CGSCM, the research aims to solve the optimization problem in CGSCM. Considering the two aspects, economic and environmental performance, the optimization objective is to maximize the aggregate net profit of the entire supply chain. Economic performance involves cost and revenue in various nodes of the physical flow process, which are divide into normalized construction logistics net profit and reverse logistics aggregate cost. Environmental performance refers to the recycling of the waste construction materials and it leads to the corresponding benefit. The restricts in the problem are oriented from self-control and the influence of adjacent nodes

Considering the complexity of GSCM, the model assumptions include: (1)Specifying the study scope includes supplier of construction raw-materials, supplier of construction materials, construction enterprise, project owners, reprocessed center of construction materials, environmental protection agency of the government, final disposal location; (2)The unit interval engineering quantities from different project departments are given; (3)Return ratio is given, referring to the proportion of the quantity of waste construction materials returned from project departments; (4)Redundant construction materials and equipment will return to recycling center; Construction materials processed by reprocessed center of construction materials return to supplier of construction materials in the form of construction raw-materials; (5)Facility capacities associated with chain members of the model are 
known; (6)The lead-time associated with each chain member either in the general supply chain or in the reverse logistics chain is given; (7) Environmental performance refers to the saving of environmental cost in the reverse logistics because the recycling of the waste construction materials in construction is considered.

\subsection{Mathematical Model Formulation}

According to the organizational structure of CGSCM, the composite multi-objective function $(\Omega)$ contains normalized construction logistics net profit $\left(N P_{c c}\right)$ maximization, reverse logistics aggregate cost $\left(A C_{r c}\right)$ minimization, and the environmental performance $\left(E P_{r c}\right)$. Accordingly, decision variables are seen in Table 1, and other definitions of variables and parameters are summarized in appendix A. The mathematical form of function is:

$M a x \Omega=N P_{c c}-A C_{r c}+E P_{r c}$

\subsubsection{Normalized construction logistics constraints}

Normalized construction logistics includes aggregate revenue $\left(A R_{c c}\right)$ and aggregate cost $\left(A C_{c c}\right)$.

$0 \leq N P_{c c} \leq A R_{c c}-A C_{c c}$,

and the aggregate revenue is from the supplier of construction raw-materials $\left(A R_{\text {scr }}\right)$, the supplier of construction materials $\left(A R_{s c m}\right)$, supplier of equipment leasing $\left(A R_{\text {sel }}\right)$, construction enterprise $\left(A R_{c e}\right)$

$0 \leq A R_{c c} \leq A R_{s c r}+A R_{s c m}+A R_{s e l}+A R_{c e}$,
$0 \leq A R_{s c r} \leq \sum_{t=1}^{T} \sum_{s c r} \sum_{s c m} r_{s c r, s c m}(t) \times Q_{s c r, s c m}(t)$,

where aggregate revenue of construction raw-materials $\left(A R_{s c r}\right)$ is oriented primarily from the flows of the construction raw-materials product $\left(Q_{s c r, s c m}(t)\right)$,

$0 \leq A R_{s c m} \leq \sum_{t=1}^{T} \sum_{s c m} \sum_{c e} r_{s c m, c e}(t) \times Q_{s c m, c e}(t)$,

where aggregate revenue of construction materials $\left(A R_{\mathrm{scm}}\right)$ is oriented primarily from the flows of the construction materials product $\left(Q_{\text {scm,ce }}(t)\right)$

$0 \leq A R_{\text {sel }} \leq \sum_{t=1}^{T} \sum_{\text {sel }} \sum_{c e} r_{\text {sel,ce }}(t) \times Q_{\text {sel,ce }}(t)$,

where aggregate revenue of equipment leasing $\left(A R_{\text {sel }}\right)$ is oriented primarily from the flows of the equipment $\left(Q_{\text {sel,ce }}(t)\right)$,

$0 \leq A R_{c e} \leq \sum_{t=1}^{T} \sum_{c e} r_{c e}(t) \times Q_{c e}(t)$,

where the aggregate revenue of the construction enterprises are oriented from the engineering quantity ( $\left.Q_{c e}(t)\right)$.

Aggregate cost $\left(A C_{c c}\right)$ includes the aggregate physical flow procurement cost ( $\left.A P C_{c c}\right)$, the aggregate production cost of construction materials $\left(A P C_{s c m}\right)$, the aggregate transportation cost $\left(A T C_{c c}\right)$, the 
aggregate inventory cost $\left(A I C_{c c}\right)$, the aggregate project cost of construction enterprise $\left(A C C_{c e}\right)$, the aggregate recycling fee ( $A G F$ )

$$
\begin{aligned}
A C_{c c} \geq & A P C_{c c}+A P C_{s c m}+A T C_{c c}+A I C_{c c}+A C C_{c e}+A G F, \\
A P C_{c c} \geq & \sum_{t=1}^{T} \sum_{s c r} c_{s c r}^{r a w}(t) \times Q_{s c r}^{r a w}(t)+\left[\sum_{t=1}^{T} \sum_{s c r} \sum_{s c m} c_{s c r, s c m}^{p r o}(t) \times Q_{s c r, s c m}(t)+\sum_{t=1}^{T} \sum_{s c m} c_{r e p, s c m}^{p r o}(t) \times Q_{r e p, s c m}(t)+\right. \\
& \left.\sum_{t=1}^{T} \sum_{\text {rec }} \sum_{s c m} c_{r e c, s c m}^{p r o}(t) \times Q_{r e c, s c m}(t)\right]+\sum_{t=1}^{T} \sum_{s c m} \sum_{c e} c_{s c m, c e}^{p r o}(t) \times Q_{s c m, c e}(t)+\sum_{t=1}^{T} \sum_{s e l} \sum_{c e} c_{\text {sel }, c e}^{p r o}(t) \times Q_{s e l, c e}(t),
\end{aligned}
$$

where the aggregate physical flow procurement cost $\left(A P C_{c c}\right)$ involves four components: (1) the initialized cost of construction raw-materials generated in the supplier of construction raw-materials; (2) the procurement cost for ordering the construction raw-materials from the supplier of construction raw-materials, reprocessed center of construction materials in the reverse chain and recycling center in the interior of the construction enterprise; (3) the procurement cost for ordering the construction materials from the supplier of construction materials; (4) the procurement cost for leasing the equipment from supplier of equipment leasing.

$$
A P C_{s c m} \geq \sum_{t=1}^{T} \sum_{s c m} c_{s c m}^{p r o}(t) \times Q_{s c m, c e}(t),
$$

where the aggregate production cost of construction materials $\left(A P C_{s c m}\right)$ is oriented primarily from construction materials product of $\left(Q_{\text {scm,ce }}(t)\right)$.

$$
\begin{aligned}
& A T C_{c c} \geq \sum_{t=1}^{T}\left\{\left[\sum_{s c r} \sum_{s c m} c_{s c r, s c m}^{t r a}(t) \times Q_{s c r, s c m}(t)\right]+\left[\sum_{s c m} \sum_{c e} c_{s c m, c e}^{t r a}(t) \times Q_{s c m, c e}(t)\right]+\left[\sum_{s e l} \sum_{c e} c_{s e l, c e}^{t r a}(t) \times Q_{s e l, c e}(t)\right]\right. \\
& +\left[\sum_{c e} \sum_{\text {rec }} c_{c e, \text { rec }}^{\text {mita }}(t) \times Q_{c e, \text { rec }}^{m}(t)\right]+\left[\sum_{c e} \sum_{\text {rec }} c_{c e, \text { rec }}^{\text {etra }}(t) \times Q_{c e, \text { rec }}^{e}(t)\right]+\left[\sum_{\text {rec ce }} \sum_{c} c_{\text {rec }, e e}^{\text {mra }}(t) \times Q_{\text {rec, }, e}^{m}(t)\right]+
\end{aligned}
$$

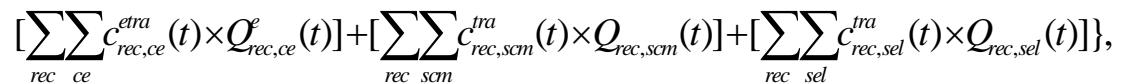

where the aggregate transportation $\operatorname{cost}\left(A T C_{c c}\right)$ of the given normalized construction logistics is oriented from nine types: (1) the construction raw-materials $\left(Q_{s c r, s c m}(t)\right)$ transported from the supplier of the construction raw-materials to the supplier of the construction materials; (2) the construction materials $\left(Q_{\text {scm,ce }}(t)\right)$ transported from the supplier of the construction materials to the construction enterprise; (3) the equipment $\left(Q_{\text {sel,ce }}(t)\right)$ transported from supplier of equipment leasing to the construction enterprise; (4) the construction materials $\left(Q_{c e, r e c}^{m}(t)\right)$ transported from the construction enterprise to recycling center; (5) the equipment $\left(Q_{c e \text {,rec }}^{e}(t)\right)$ transported from the construction enterprise to recycling center; (6) the construction materials $\left(Q_{\text {rec,ce }}^{m}(t)\right)$ transported from recycling center to the construction enterprise; (7) the equipment $\left(Q_{\text {rec,ce }}^{e}(t)\right)$ transported from recycling center to the construction enterprise; (8) the construction materials $\left(Q_{\text {rec,scm }}(t)\right)$ transported from recycling center to the supplier of the construction materials; and (9) the equipment $\left(Q_{\text {rec,sel }}(t)\right)$ transported from recycling center supplier of equipment leasing.

$$
\begin{aligned}
A I C_{c c} & \geq \sum_{t=1}^{T}\left\{\left[\sum_{s c r} c_{s c r}^{r a w i n v}(t) \times Q_{s c r}^{r a w i n v}(t)\right]+\left[\sum_{s c m} c_{s c m}^{r a w i n v}(t) \times Q_{s c m}^{r a w i n v}(t)\right]+\left[\sum_{s c m} c_{s c m}^{i n v}(t) \times Q_{s c m}^{i n v}(t)\right]\right. \\
+ & {\left.\left[\sum_{r e c} c_{r e c}^{\text {minv }}(t) \times Q_{r e c}^{\text {minv }}(t)\right]+\left[\sum_{\text {sel }} c_{s e l}^{i n v}(t) \times Q_{s e l}^{i n v}(t)\right]+\left[\sum_{r e c} c_{r e c}^{\text {einv }}(t) \times Q_{r e c}^{\text {einv }}(t)\right]\right\}, }
\end{aligned}
$$


where the aggregate inventory cost $\left(A I C_{c c}\right)$ is mainly caused by the storage of six types of physical flows: (1) construction raw-materials in supplier of construction raw-materials $\left(Q_{s c r}^{\text {rawinv }}(t)\right)$; (2) construction raw-materials in supplier of construction materials $\left(Q_{s c m}^{\text {rawinv }}(t)\right)$; (3) construction materials in supplier of construction materials $\left(Q_{s c m}^{\text {inv }}(t)\right)$; (4) construction materials in recycling center $\left(Q_{\text {rec }}^{\min }(t)\right)$; (5) the equipment in supplier of equipment leasing $\left(Q_{s e l}^{i n v}(t)\right)$; $(6)$ the equipment in recycling center ( $\left.Q_{\text {rec }}^{\text {einv }}(t)\right)$.

$A C C_{c e} \geq \sum_{t=1}^{T} \sum_{c e} c_{c e}(t) \times Q_{c e}(t)$,

where the aggregate cost of the construction enterprises are oriented from the engineering quantity ( $\left.Q_{c e}(t)\right)$.

$A G F \geq \sum_{t=1}^{T} \sum_{c e} f^{r e}(t) \times Q_{c e}(t)$

where the aggregate recycling fee $(A G F)$ are oriented from the engineering quantity $\left(Q_{c e}(t)\right)$ multiplied by the corresponding unit recycling fee.

\subsubsection{Reverse logistics constraints}

Reverse logistics aggregate cost includes, the aggregate re-processing cost of the waste construction materials $\left(A R C_{r c}\right)$, the aggregate transportation cost $\left(A T C_{r c}\right)$, the aggregate inventory cost ( $\left.A I C_{r c}\right)$, the aggregate final disposal cost ( $A F C_{r c}$ ), the aggregate subsidies from environmental protection agency ( $\left.A G S_{r c}\right)$, the aggregate revenue from supplier of construction materials $\left(A M R_{r c}\right)$, revenue and cost constraints are seen in Eqs. (15) (21).

$$
\begin{aligned}
& A C_{r c} \geq A R C_{r c}+A T C_{r c}+A I C_{r c}+A F C_{r c}-\left(A G S_{r c}+A M R_{r c}\right), \\
& A R C_{r c} \geq \sum_{t=1}^{T} c_{r e p}^{r e p}(t) \times Q_{r e p}^{r e p}(t),
\end{aligned}
$$

where the aggregate re-processing cost of the waste construction materials ( $\left.A R C_{r c}\right)$ is caused due to the transitional treatment procedures in the reprocessed center of construction materials.

$$
A T C_{r c} \geq \sum_{t=1}^{T}\left\{\left[\sum_{s c m} c_{r e p, s c m}^{\text {tra }}(t) \times Q_{\text {rep }, \text { scm }}(t)\right]+\left[\sum_{c e} c_{c e, \text { rep }}^{\text {tra }}(t) \times Q_{\text {ce, rep }}(t)\right]+\left[c_{r e p, \text { fin }}^{\text {tra }}(t) \times Q_{\text {rep , fin }}(t)\right]\right\},
$$

where the aggregate transportation cost $\left(A T C_{r c}\right)$ involves the costs of transporting physical flows in the given reverse chain.

$$
A I C_{r c} \geq \sum_{t=1}^{T}\left\{\left[c_{r e p}^{\text {uninv }}(t) \times Q_{\text {rep }}^{\text {uninv }}(t)\right]+\left[c_{r e p, s c m}^{\text {prinv }}(t) \times Q_{\text {rep }, \text { scm }}^{\text {priv }}(t)\right]+\left[c_{r e p, \text { fin }}^{\text {priv }}(t) \times Q_{r e p, \text { fin }}^{\text {prinv }}(t)\right]\right\},
$$

where the aggregate inventory cost $\left(A I C_{r c}\right)$ is mainly caused by the storage of three types of physical flows, the amount of given waste construction materials that have not been treated by the given reprocessed center of construction materials $\left(Q_{\text {rep }}^{\text {uninv }}(t)\right)$, the inventory amount of given waste construction materials that have been treated by the given reprocessed center of construction materials from reprocessed center of construction materials to supplier of construction materials $\left(Q_{\text {rep scrm }}^{\text {prin }}(t)\right)$, and the inventory amount of given waste construction materials that have been treated by the given reprocessed center of construction materials from reprocessed center of construction materials to final disposal location $\left(Q_{\text {rep, fin }}(t)\right)$.

$$
A F C_{r c} \geq \sum_{t=1}^{T} c_{\text {fin }}^{\text {fin }} \times Q_{\text {rep, fin }}(t) \text {, }
$$


where the aggregate final disposal cost $\left(A F C_{r c}\right)$ depends on the total amount of waste disposed in the final disposal.

$$
0 \leq A G S_{r c} \leq \sum_{t=1}^{T} \sum_{c e} s_{\text {rep }} \times Q_{c e, \text { rep }}(t)
$$

where the aggregate subsidies from environmental protection agency ( $\left.A G S_{r c}\right)$ are oriented from the flows $\left(Q_{\text {ce,rep }}(t)\right)$.

$0 \leq A M R_{r c} \leq \sum_{t=1}^{T} \sum_{s c m} r_{r e p, s c m}(t) \times Q_{r e p, s c m}(t)$,

where the aggregate revenue from supplier of construction materials $\left(A M R_{r c}\right)$ is oriented from the flows $\left(Q_{\text {rep }, \text { scm }}(t)\right)$.

\section{Table 1}

Decision variables of the model

\begin{tabular}{|c|c|}
\hline$Q_{\text {scr,scm }}(t)$ & $\begin{array}{l}\text { The time-varying amount of construction raw-materials from supplier of construction raw- } \\
\text { materials to supplier of construction materials }\end{array}$ \\
\hline$Q_{s c m, c e}(t)$ & $\begin{array}{l}\text { The time-varying amount of construction materials from supplier of construction materials } \\
\text { to project department of construction enterprise }\end{array}$ \\
\hline$Q_{s e l, c e}(t)$ & $\begin{array}{l}\text { The time-varying amount of equipments from supplier of equipment leasing to project } \\
\text { department of construction enterprise }\end{array}$ \\
\hline$Q_{\text {rec,scm }}(t)$ & $\begin{array}{l}\text { The time-varying amount of construction materials from recycling center to supplier of } \\
\text { construction materials }\end{array}$ \\
\hline$Q_{\text {rec,sel }}(t)$ & $\begin{array}{l}\text { The time-varying amount of equipments from recycling center to supplier of equipment } \\
\text { leasing }\end{array}$ \\
\hline$Q_{\text {scm }}(t)$ & $\begin{array}{l}\text { The time-varying amount of construction materials generated by supplier of construction } \\
\text { materials }\end{array}$ \\
\hline$Q_{\text {rep }}^{\text {rep }}(t)$ & $\begin{array}{l}\text { The time-varying amount of reprocessing waste construction materials associated with } \\
\text { reprocessed center of construction materials }\end{array}$ \\
\hline$Q_{\text {rep, scm }}(t)$ & $\begin{array}{l}\text { The time-varying amount of the physical flow returned from reprocessed center of } \\
\text { construction materials to supplier of construction materials }\end{array}$ \\
\hline$Q_{\text {rep, fin }}(t)$ & $\begin{array}{l}\text { The time-varying final disposal amount of useless materials from reprocessed center of } \\
\text { construction materials to final disposal location }\end{array}$ \\
\hline$Q_{s c m}^{i n v}(t)$ & $\begin{array}{l}\text { The time-varying inventory amount of construction materials in a given supplier of } \\
\text { construction materials }\end{array}$ \\
\hline$Q_{s e l}^{i n v}(t)$ & The time-varying inventory amount of equipments in a given supplier of equipment leasing \\
\hline$Q_{\text {scr }}^{\text {raw }}(t)$ & $\begin{array}{l}\text { The time-varying amount of construction raw-materials generated by supplier of } \\
\text { construction raw-materials }\end{array}$ \\
\hline$Q_{c e, \text { epp }}(t)$ & $\begin{array}{l}\text { The time-varying amount of waste construction materials from project department of } \\
\text { construction enterprise to reprocessed center of construction materials }\end{array}$ \\
\hline
\end{tabular}

\subsubsection{Inventory constraints}

Facility capacities associated with chain members of the model are given, inventory constraints are seen in Eqs. (22) (31).

$0 \leq Q_{s c r}^{\text {rawinv }}(t)=Q_{s c r}^{\text {rawinv }}(t-1)+Q_{s c r}^{\text {raw }}(t)-\sum_{s c m} Q_{s c r, s c m}(t) \leq u_{1}, \quad \forall t, s c r, s c m$

where the time-varying inventory amount $\left(Q_{s c r}^{\text {rawinv }}(t)\right)$ of construction raw-materials in a given supplier of construction raw-materials in a given time interval $t$ is equal to the sum of the corresponding inventory amount remaining in the previous time interval $\left(Q_{s c r}^{\text {rawinv }}(t-1)\right)$ and the corresponding time- 
varying amount $\left(Q_{s c r}^{\text {raw }}(t)\right)$ of construction raw-materials generated by supplier of construction rawmaterials, minus the total outbound construction raw-materials flow $\left(\sum_{\forall s c m} Q_{s c r, s c m}(t)\right)$ transported to the supplier of construction materials. In addition, $Q_{s c r}^{\text {rawinv }}(t)$ is subject to predetermined upper and lower bounds, the storage capacity $\left(u_{1}\right)$ and 0 .

$$
\begin{aligned}
& 0 \leq Q_{s c m}^{\text {rawinv }}(t)=Q_{s c m}^{\text {rawinv }}(t-1)+\left[Q_{r e p, s c m}(t)+\sum_{s c r} Q_{s c r, s c m}(t)\right]-\tau_{s c m}^{r / m} \times Q_{s c m}(t) \leq u_{2}, \quad \forall s c m, r e p, s c r, t \\
& 0 \leq Q_{s c m}^{i n v}(t)=Q_{s c m}^{i n v}(t-1)+Q_{s c m}(t)-\sum_{c e} Q_{s c m, c e}(t) \leq u_{3}, \quad \forall s c m, c e, t
\end{aligned}
$$

Similar to the rationales of Eq. (23), the time-varying inventory amount $\left(Q_{s c m}^{\text {rawinv }}(t)\right)$ of construction raw-materials in a given supplier of construction materials should be subject to predetermined upper and lower bounds. In addition, logistics flows from the reprocessed center of construction materials and the logistics flows transformed from construction raw-materials to construction materials are considered, the corresponding coefficient $\tau_{s c m}^{r / m}$ is involved in Eq. (23). Similarly, the time-varying inventory amount of construction materials in a given supplier of construction materials $\left(Q_{s c m}^{i n v}(t)\right)$ is defined in Eq. (24).

$$
\begin{aligned}
& 0 \leq Q_{s e l}^{i n v}(t)=Q_{s e l}^{i n v}(t-1)-\sum_{c e} Q_{s e l, c e}(t) \leq u_{4}, \quad \forall t, \text { sel,ce } \\
& 0 \leq Q_{r e c}^{m \_i n v}(t)=Q_{r e c}^{m \_i n v}(t-1)+\sum_{c e} Q_{c e, r e c}^{m}(t)-\sum_{c e} Q_{r e c, c e}^{m}(t)-\sum_{s c m} Q_{r e c, s c m}(t) \leq u_{5}, \quad \forall t, r e c, c e, s c m \\
& 0 \leq Q_{r e c}^{e \_i n v}(t)=Q_{r e c}^{e \_i n v}(t-1)+\sum_{c e} Q_{c e, r e c}^{e}(t)-\sum_{c e} Q_{r e c, c e}^{e}(t)-\sum_{s e l} Q_{r e c, s e l}(t) \leq u_{6}, \quad \forall r e c, c e, s e l, t
\end{aligned}
$$

Similarly, the upper and the lower bounds associated with supplier of equipment leasing and recycling center are considered.

$$
\begin{aligned}
& 0 \leq Q_{\text {rep }}^{\text {uninv }}(t)=Q_{\text {rep }}^{\text {uninv }}(t-1)-Q_{\text {rep }}^{\text {rep }}(t)+\sum_{c e} Q_{c e, \text { rep }}(t) \leq u_{7}, \quad \forall \text { rep, ce, } t
\end{aligned}
$$

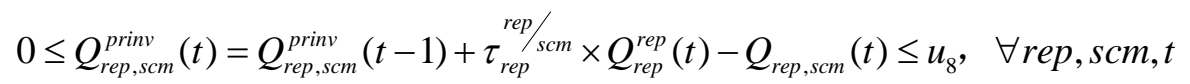

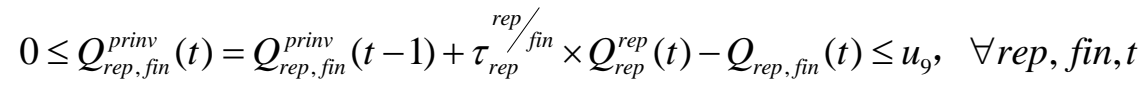

$$
\begin{aligned}
& \tau_{\text {rep }}^{\text {rep } / \text { scm }}+\tau_{\text {rep }}^{\text {rep }} / \text { fin }=1
\end{aligned}
$$

In contrast with above boundary constrains, the reprocessed waste materials may have two distribution channels: one leading to supplier of construction materials and the other leading to final disposal. The

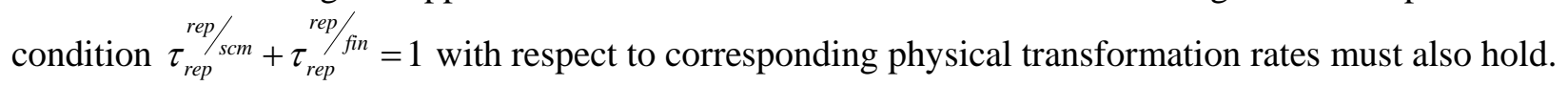

\subsubsection{Environmental performance constraints}

$$
E P_{r c}=\omega \times \sum_{t=1}^{T} \sum_{c e} \sum_{r e p} Q_{c e, \text { rep }}(t)
$$

where the environmental performance $\left(E P_{r c}\right)$ is oriented from the amount $\left(\sum_{t=1}^{T} \sum_{c e} \sum_{\text {rep }} Q_{c e, \text { rep }}(t)\right)$ of waste construction materials from construction enterprise to reprocessed center of construction materials in a given time interval $t$ multiplied by the unit environmental performance. 


\subsubsection{Other constraints}

The time-varying engineering quantities are represented by corresponding consuming construction materials, and there is the ratio $r$, between the amount of recycling waste construction materials and engineering quantities. Constraints are seen in Eq. (33) and Eq. (34).

$$
\begin{aligned}
& 0 \leq Q_{c e}(t)=\sum_{s c m} Q_{s c m, c e}(t), \forall c e, s c m, t \\
& \sum_{\text {rep }} Q_{c e, r e p}(t)=r \times Q_{c e}, \forall c e, r e p, t
\end{aligned}
$$

The constrains denote the time-varying relationships among the engineering quantity $\left(Q_{c e}\right)$ associated with project departments, the predetermined waste construction materials return ratio $(r)$, the total amount of construction materials from supplier of construction materials to project department of construction enterprise $\left(\sum_{s c m} Q_{s c m, c e}(t)\right)$, the total amount of waste construction materials from project department of construction enterprise to reprocessed center of construction materials $\left(\sum_{\text {rep }} Q_{c e, \text { rep }}(t)\right)$.

\section{Experiments and Analysis}

\subsection{Experiment Design and Data collection}

To illustrate the applicability of the proposed model, a completed construction engineering numerical case was conducted. We interview constriction enterprise with its supply chain members to acquire data, and achieve corresponding parameters by collecting historical data, e.g., engineering quantity, waste construction materials returns, the profits and cost in the supply chain members, the unit amount of government subsidies and recycling fee, storage capacities and logistics operational costs in CGSCM. The initial unit amount of recycling waste construction materials corresponding to environmental performance is set with 50, the unit subsidy is set with 150 RMB. The case has two construction raw-materials suppliers, two construction materials suppliers, two equipment leasing suppliers, one construction enterprise, two project departments, one construction materials reprocessed center, two finial disposal locations. Given that the time interval $(t)$ is defined by one month, and the planning period is one year. The experiment model is composed of 377 time-varying decision variables and corresponding 516 respective constraints. IBM ILOG CPLEX 12.2 optimization studio was employed to solve it.

\subsection{Parameters Setting}

We summarized all the collected data and estimated the upper and lower bounds. The corresponding upper and lower bounds were specified using the aforementioned survey data. The primary parameters are summarized in Table 2. The estimated ranges of the corresponding unit revenues and costs associated with normalized construction logistics and reverse logistics are summarized in Table 3.

Table 2

\begin{tabular}{|c|c|c|c|c|c|c|c|c|c|}
\hline \multirow[t]{2}{*}{ Transformation rate } & $\tau_{\text {rep }}^{\text {rep } / \text { scm }}$ & 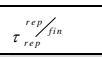 & \multicolumn{7}{|c|}{$\tau_{s c m}^{r / m}$} \\
\hline & 0.5 & 0.5 & 0.5 & & & & & & \\
\hline \multirow[t]{2}{*}{ Inventory capability } & $u_{1}$ & $u_{2}$ & $u_{3}$ & $u_{4}$ & $u_{5}$ & $u_{6}$ & $u_{7}$ & $u_{8}$ & $u_{9}$ \\
\hline & 1000 & 1000 & 1000 & 10 & 100 & 10 & 100 & 100 & 100 \\
\hline \multirow[t]{2}{*}{ Others } & $r$ & $f^{r e}(t)$ & $s_{r e p}$ & $\omega$ & $c_{f i n}^{f i n}$ & $Q_{c e}(t)$ & & & \\
\hline & 0.5 & 37 & 150 & 50 & 200 & 1000 & & & \\
\hline
\end{tabular}

Primary parameters 


\subsection{Numerical Results and Analysis}

To analyze the model performance, the paper compares the proposed model to the supply chain system without the integrated optimization, where the supply chain members make decisions according to maximizing their separate interests. The experimental results are summarized in Table 4 , the increases of normalized construction logistics profit reaches more than $20 \%$, it may result mainly from the efficiency in coordinating construction supply chain operations of chain members and reducing logistics costs. The increased aggregate profit is still more than $10 \%$ when the reverse logistics and the corresponding environmental performance are considered. It shows that the proposed CGSCM model benefits the accomplishment of "Green" without extra expenses charged to any members involved in the construction green supply chain.

\section{Table 3}

Estimated ranges of the corresponding unit revenues and costs associated with normalized construction logistics and reverse logistics in the case (Unit: RMB)

\begin{tabular}{|c|c|c|}
\hline Node members & Parameters: Unit revenues & Parameters: Unit revenues \\
\hline \multirow{2}{*}{$\begin{array}{l}\text { Supplier of construction } \\
\text { raw-materials }\end{array}$} & $r_{\text {scr,scm }}(t): 300 \sim 400$ & $c_{s c r}^{r a w}(t): 80 \sim 100$ \\
\hline & $c_{\text {scr }}^{\text {rawinv }}(t): 30 \sim 40$ & $c_{s c r, s c m}^{t r a}(t): 100$ \\
\hline \multirow{4}{*}{$\begin{array}{l}\text { Supplier of construction } \\
\text { materials }\end{array}$} & $r_{\text {scm,ce }}(t): 400 \sim 5200$ & $c_{\text {scr, scm }}^{\text {pro }}(t): 300 \sim 400$ \\
\hline & $c_{\text {rec }, \text { scm }}^{\text {pro }}(t): 400 \sim 5100$ & $c_{r e p, s c m}^{p r o}(t): 300 \sim 400$ \\
\hline & $c_{\text {scm }}^{\text {pro }}(t): 350 \sim 2000$ & $c_{s c m, c e}^{t r a}(t): 100$ \\
\hline & $c_{\text {scm }}^{\text {rawinv }}(t): 30 \sim 40$ & $c_{s c m}^{i n v}(t): 200 \sim 1700$ \\
\hline \multirow{2}{*}{$\begin{array}{l}\text { Supplier of equipment } \\
\text { leasing }\end{array}$} & $r_{s e l, c e}(t): 16000 \sim 35000$ & $c_{\text {sel,ce }}^{\text {tra }}(t): 100$ \\
\hline & $c_{\mathrm{sel}}^{i n v}(t): 7000 \sim 15000$ & \\
\hline \multirow[t]{7}{*}{ Construction enterprise } & $r_{c e}(t): 1800$ & $c_{s c m, c e}^{p r o}(t): 400 \sim 5200$ \\
\hline & $c_{s c l, c e}^{p r o}(t): 16000 \sim 35000$ & $c_{c e, r e c}^{m r r a}(t): 50 \sim 60$ \\
\hline & $c_{c e, r e c}^{\text {etra }}(t): 20$ & $c_{\text {rec, }, e}^{m+r a}(t): 50 \sim 60$ \\
\hline & $c_{\text {rec, }, e e}^{\text {etra }}(t): 20$ & $c_{r e c, s c m}^{t r a}(t): 100$ \\
\hline & $c_{r e c, s e l}^{t r a}(t): 100$ & $c_{\text {rec }}^{\operatorname{minv}}(t): 100$ \\
\hline & $c_{r e c}^{e i n v}(t): 60$ & $c_{c e}(t): 180 \sim 190$ \\
\hline & $c_{c e, \text { rep }}^{\text {tra }}(t): 90$ & \\
\hline \multirow{4}{*}{$\begin{array}{l}\text { Reprocessed center of } \\
\text { construction materials }\end{array}$} & $r_{r e p, s c m}(t): 300 \sim 400$ & $c_{\text {rep }}^{r e p}(t): 200$ \\
\hline & $c_{r e p, s c m}^{t r a}(t): 100$ & $c_{\text {rep, fin }}^{\text {tra }}(t): 90$ \\
\hline & $c_{f i n}^{f i n}: 200$ & $c_{\text {rep }}^{\text {uninv }}(t): 80$ \\
\hline & $c_{r e p, s c m}^{\text {prinv }}(t): 80$ & $c_{r e p, f i n}^{p r i n v}(t): 80$ \\
\hline
\end{tabular}

\section{Table 4}

Evaluation of relative system performance (Unit: RMB)

\begin{tabular}{|c|c|c|c|c|}
\hline & $\begin{array}{l}\text { construction supply } \\
\text { chain-based net profit }\end{array}$ & $\begin{array}{l}\text { Reverse chain-based } \\
\text { aggregate cost }\end{array}$ & $\begin{array}{l}\text { Reverse chain-based } \\
\text { environmental performance }\end{array}$ & Aggregate \\
\hline $\begin{array}{l}\text { Existing operational } \\
\text { system }\end{array}$ & $3,427,200$ & - & - & $3,427,200$ \\
\hline Proposed method & $4,167,200$ & 507,900 & 172,400 & $3,831,700$ \\
\hline Relative improvement & $21.59 \%$ & - & - & $11.80 \%$ \\
\hline
\end{tabular}

\subsection{Factors Analysis}

The relative parameters $\left(r, s_{\text {rep }} \& \omega\right)$ to investigate the potential effects on the performance of the supply chain are discussed. It can be seen in Fig. 3: 1) Proper government subsidies can improve the 
aggregate profit of the supply chain without extra expenses from the government, which is beneficial for the implement of CGSCM such as the unit subsidies 150 in the case; 2) With the environmental performance of reverse logistics $\omega$ improving, the aggregate profit of the supply chain is increased, and the return ratio $r$ has a tendency to increase, which is beneficial for CGSCM. As a result, strengthening the environmental performance can promote the implement of CGSCM; 3) Comparing the two figures in the Fig. 3, it can be concluded that there is an optimal value for the return ratio which maximizes the net profit of the whole supply chain when the government subsidies or environmental performance is appropriate. For example, when the environmental performance is 50, the value of return ratio 0.6 makes the objective function maximum.

\section{Conclusion}

GSCM is an important content and a way to save energy and to reduce pollution in construction industry. Based on the organizational structure of CGSCM to coordinate normalized construction logistics and the reverse logistics, an optimization model was proposed. The key factors such as the environmental performance and subsidies from governmental organizations were discussed. Numerical studies indicate that CGSCM could improve the aggregate profit of the supply chain effectively. In addition, appropriate reverse logistics return ratio, subsidy strategies and environmental performance would be beneficial for the implement of CGSCM.
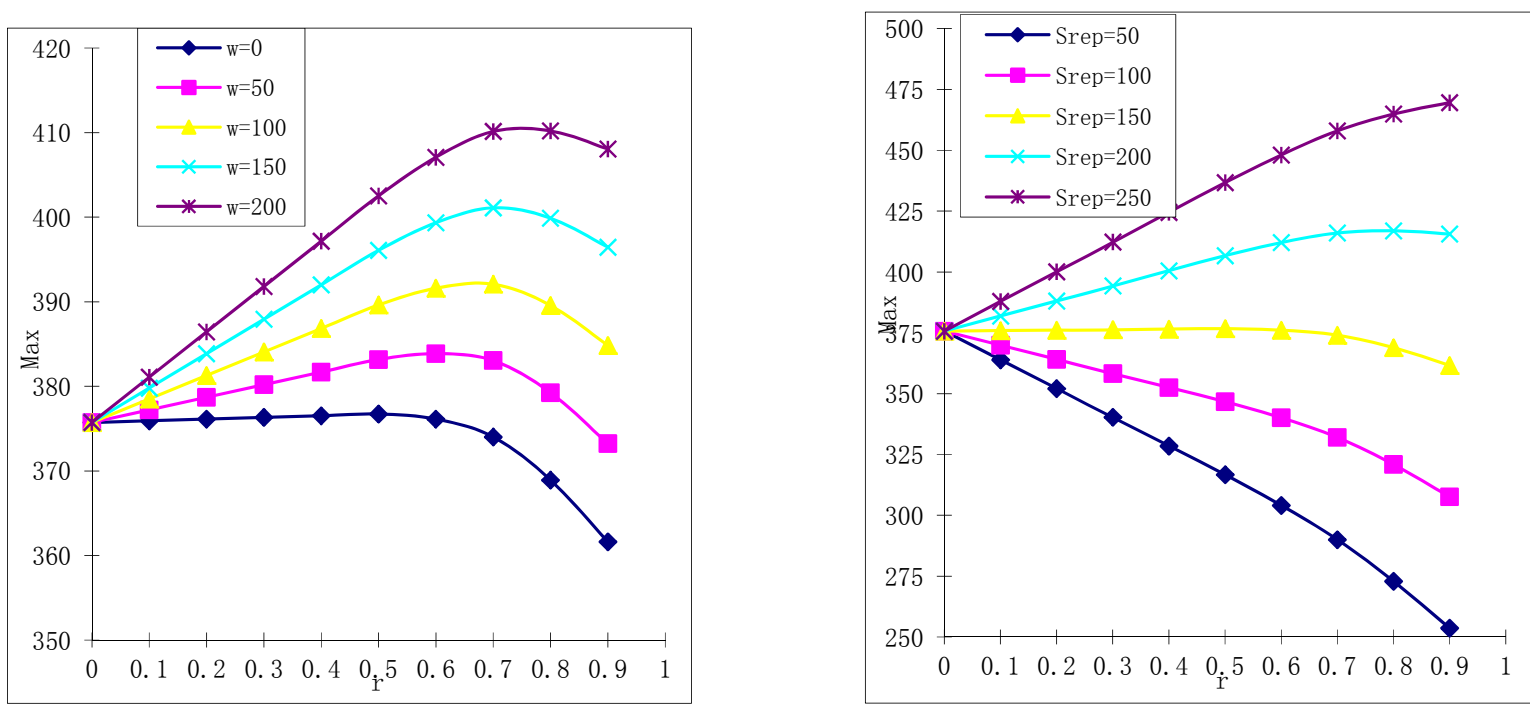

Fig. 3. Control parameter analyses $\left(\omega, s_{\text {rep }}, r\right.$ with $\left.\operatorname{Max} \Omega\right)$

\section{References}

Ander, E., Roger, B., Aitor, O., \& Javier, S.(2007). A process for developing partnerships with subcontractors in the construction industry: An empirical study. International Journal of Project Management, 25, 250-256.

Ekambaram, P., Mohan K., Motiar R., \& Thomas, N.(2003). Curing congenital construction industry disorders through relationally integrated supply chains. Building and Environment, 38, 571-582.

Francesco, T., \& Fabio, I. (2010). Shadows and lights of GSCM (Green Supply Chain Management): determinants and effects of these practices based on a multi-national study. Journal of Cleaner Production, 18, 953-962.

Hsiao-Fan, W., \& Hsin-Wei, H.(2010). A closed-loop logistic model with a spanning-tree based genetic algorithm. Computers \& Operations Research, 37, 376 - 389.

Jack C.P. Cheng, Kincho H. Law, Hans B., Albert J., \& Ram D. S.(2010). Modeling and monitoring of construction supply chains. Advanced Engineering Informatics, 24, 435-455 
Jiuh-Biing, S. (2008). Green supply chain management, reverse logistics and nuclear power generation. Transportation Research Part E, 44, 19-46.

Jiuh-Biing, S., Yi-Hwa, C., \& Chun-Chia, H.(2005). An integrated logistics operational model for green supply chain management. Transportation Research Part E, 41, 287-313.

Marta, G., Miquel, C., Santiago, G., Nuria, F., Xavier, R., \& Alba F.(2009). A methodology for predicting the severity of environmental impacts related to the construction process of residential buildings. Building and Environment, 44, 558- 571

Ruben, V., \& Lauri, K.(2000). The four roles of supply chain management in construction European. Journal of Purchasing \& Supply Management, 6, 169-178.

Turan, P., Tolga B., Eren O.(2011). Operational and environmental performance measures in a multiproduct closed-loop supply chain. Transportation Research Part E, 47, 532-546.

Xiao Dong, L., Yi Min Z., \& Zhi Hui, Z. (2010). An LCA-based environmental impact assessment model for construction processes. Building and Environment, 45, 766 - 775.

Xian Hai, M. (2010). Assessment framework for construction supply chain relationships: Development and evaluation. International Journal of Project Management, 28, 695-707.

Yao Wu, W., \& Xiao Long, X.(2004). The application of supply chain management in construction industry. China Civil Engineering Journal, 37, 86-91.

Yenming, J.C., \& Jiuh-Biing, S.(2009). Environmental-regulation pricing strategies for green supply chain management. Transportation Research Part E, 45, 667-677.

Zhao Hui, W., \& Mark, P.(2011). Balancing priorities: Decision-making in sustainable supply chain management. Journal of Operations Management, 29, 577-590.

Appendix A.

Definitions of model variables and parameters

Function

$\Omega \quad$ The proposed composite multi-objective function

$N P_{c c} \quad$ The normalized construction logistics profit function

$A C_{r c} \quad$ The reverse logistics aggregate cost function

Dependent variable

$Q_{c e}(t) \quad$ The time-varying engineering quantity associated with project departments

$Q_{c e, r e c}^{e}(t) \quad$ The time-varying amount of redundant equipments from project departments to recycling center

$Q_{c e, r e c}^{m}(t)$ The time-varying amount of redundant construction materials from project departments to recycling center

$Q_{\text {rec,e }}^{m}(t)$ The time-varying amount of redundant construction materials from recycling center to project departments

$Q_{r e c, e c}^{e}(t) \quad$ The time-varying amount of redundant equipments from recycling center to project departments

$Q_{s c r}^{\text {rawiv }}(t) \quad$ The time-varying inventory amount of construction raw-materials in a given supplier of construction raw-materials

$Q_{s c m}^{\text {rawin }}(t) \quad$ The time-varying inventory amount of construction raw-materials in a given supplier of construction materials

$Q_{r e c}^{\text {minv }}(t) \quad$ The time-varying inventory amount of construction materials in a given recycling center

$Q_{\text {rec }}^{\text {einv }}(t) \quad$ The time-varying inventory amount of equipments in a given recycling center

$Q_{r e p}^{\text {uminv }}(t) \quad$ The time-varying inventory amount of given waste construction materials that have not been treated by the given reprocessed center of construction materials

$Q_{q p, s m}^{\text {pim }}(t) \quad$ The time-varying inventory amount of given waste construction materials that have been treated by the given reprocessed center of construction materials from reprocessed center of construction materials to supplier of construction materials

$Q_{r p p, f(n)}^{p r i n v}(t) \quad$ The time-varying inventory amount of given waste construction materials that have been treated by the given reprocessed center of construction materials from reprocessed center of construction materials to final disposal location 
Parameter

$r_{\text {scr,scm }}(t) \quad$ The time-varying unit revenue for selling the time-varying amount of physical flow from supplier of construction raw-materials to supplier of construction materials

$r_{\text {scm,ce }}(t) \quad$ The time-varying unit revenue for selling the time-varying amount of physical flow from supplier of construction materials to project departments of construction enterprise

$r_{\text {sel,ce }}(t) \quad$ The time-varying unit revenue for leasing the time-varying amount of physical flow from supplier of equipment leasing to project departments of construction enterprise

$r_{c e}(t) \quad$ The time-varying unit revenue for associated engineering quantity from project owners to construction enterprise

$c_{s c r}^{\text {raw }}(t) \quad$ The time-varying unit cost for holding the time-varying amount of the raw materials associated with supplier of construction raw-materials

$c_{s c r, s c m}^{p r o}(t) \quad$ The time-varying unit cost for procurement of the time-varying amount of physical flow from supplier of construction raw-materials to supplier of construction materials

$c_{\text {rep, scm }}^{\text {pro }}(t) \quad$ The time-varying unit cost for procurement of the time-varying amount of physical flow from reprocessed center of construction materials to supplier of construction materials

$c_{r e, s, s m}^{p r o}(t) \quad$ The time-varying unit cost for procurement of the time-varying amount of physical flow from recycling center to supplier of construction materials

$c_{\text {scm,ce }}^{\text {pro }}(t) \quad$ The time-varying unit cost for procurement of the time-varying amount of physical flow from supplier of construction materials to project departments of construction enterprise

$c_{\text {scl,ce }}^{\text {pro }}(t) \quad$ The time-varying unit cost for procurement of the time-varying amount of physical flow from supplier of equipment leasing to project departments of construction enterprise

$c_{s c m}^{\text {pro }}(t) \quad$ The time-varying unit cost for producing a given construction material by supplier of construction materials

$c_{s c r, s c m}^{\text {tra }}(t) \quad$ The time-varying unit cost for transporting the time-varying amount of physical flow from supplier of construction raw-materials to supplier of construction materials

$c_{\text {scm,ce }}^{\text {tra }}(t) \quad$ The time-varying unit cost for transporting the time-varying amount of physical flow from supplier of construction materials to project departments of construction enterprise

$c_{\text {sel, }, e}^{\text {tra }}(t) \quad$ The time-varying unit cost for transporting the time-varying amount of physical flow from supplier of equipment leasing to project departments of construction enterprise

$c_{c e, r e c}^{m \text { tra }}(t) \quad$ The time-varying unit cost for transporting the time-varying amount of construction materials from project departments of construction enterprise to recycling center

$c_{c e, r e c}^{\text {etra }}(t) \quad$ The time-varying unit cost for transporting the time-varying amount of equipment from project departments of construction enterprise to recycling center

$c_{\text {rec, }, e}^{\text {mtra }}(t) \quad$ The time-varying unit cost for transporting the time-varying amount of construction materials from recycling center to project departments of construction enterprise

$c_{\text {rec }, \text { e }}^{\text {erra }}(t) \quad$ The time-varying unit cost for transporting the time-varying amount of equipment from recycling center to project departments of construction enterprise

$c_{\text {rec }, \text { scm }}^{\text {rra }}(t) \quad$ The time-varying unit cost for transporting the time-varying amount of physical flow from recycling center to supplier of construction materials

$c_{\text {rec,sel }}^{\text {tra }}(t) \quad$ The time-varying unit cost for transporting the time-varying amount of physical flow from recycling center to supplier of equipment leasing

$c_{\text {scr }}^{\text {rawiv }}(t) \quad$ The time-varying unit inventory cost for storing a given construction raw-materials associated with supplier of construction raw-materials

$c_{\text {scm }}^{\text {rawiv }}(t) \quad$ The time-varying unit inventory cost for storing a given construction raw-materials associated with supplier of construction materials

$c_{s c m}^{i n v}(t) \quad$ The time-varying unit inventory cost for storing a given construction materials associated with supplier of construction materials

$c_{\text {rec }}^{\text {minv }}(t) \quad$ The time-varying unit inventory cost for storing a given construction materials associated with recycling center

$c_{\text {sel }}^{\text {in }}(t) \quad$ The time-varying unit inventory cost for storing a given equipment associated with supplier of equipment leasing

$c_{r e c}^{\text {einv }}(t) \quad$ The time-varying unit inventory cost for storing a given equipment associated with recycling center

$c_{c e}(t) \quad$ The time-varying unit cost for associated engineering quantity

$f^{r e}(t) \quad$ The recycling fees charged by corresponding for environmental protection agency of the government for associated unit engineering quantity

$c_{\text {rep }}^{\text {rep }}(t) \quad$ The time-varying unit cost for reprocessing the time-varying amount of waste construction materials associated with reprocessed center of construction materials

$c_{r e p, s c m}^{t r a}(t) \quad$ The time-varying unit cost for transporting the time-varying amount of physical flow from reprocessed center of construction materials to supplier of construction materials

$c_{c e, r e p}^{\text {tra }}(t) \quad$ The time-varying unit cost for transporting the time-varying amount of physical flow from project departments of construction enterprise to reprocessed center of construction materials

$c_{\text {rep, fin }}^{\text {tra }}(t) \quad$ The time-varying unit cost for transporting the time-varying amount of physical flow from reprocessed center of construction materials to final disposal location 
$c_{\text {fin }}^{\text {fin }}$ The time-varying unit cost of final disposal associated with the time-varying amount of physical flow from reprocessed center of construction materials to final disposal location

$S_{\text {rep }} \quad$ the unit subsidy of environmental protection offered by environmental protection agency of the government to reprocessed center of construction materials

$u_{i} \quad$ the generalized form of the facility capacity associated with a given chain member for the corresponding inventory item

$r \quad$ The predetermined waste construction materials return ratio

$\tau_{\text {rep }}^{\text {rep }} /$ A coefficient referring to the transformation rate with respect to the amount of construction raw-materials relative to an unit amount of corresponding waste construction materials

$\tau_{\text {rep }}^{\text {rep }}$ tin $\quad$ A coefficient referring to the transformation rate with respect to the amount of final disposal relative to an unit amount of corresponding waste construction materials

$\tau_{s c m}^{r / m} \quad$ A coefficient referring to the transformation rate with respect to the amount of construction materials relative to an unit amount of corresponding construction raw-materials

$\omega$ the unit amount of recycling waste construction materials corresponding to environmental performance 